\title{
Incidence of and risk factors for vaginal cuff dehiscence following total laparoscopic hysterectomy: a monocentric hospital analysis
}

\author{
Julia Caroline Radosa ${ }^{1}$ - Marc Philipp Radosa ${ }^{2}$. Julia Sarah Maria Zimmermann ${ }^{1}$. Eva-Marie Braun ${ }^{1}$. \\ Sebastian Findeklee ${ }^{1}$ - Annette Wieczorek ${ }^{1}$ - Lisa Stotz ${ }^{1}$. Amr Hamza ${ }^{1}$. Ferenc Zoltan Takacs ${ }^{1}$ - Uda Mareke Risius ${ }^{3}$. \\ Christoph Gerlinger ${ }^{1} \cdot$ Christoph Georg Radosa $^{4} \cdot$ Stefan Wagenpfeil ${ }^{5} \cdot$ Erich-Franz Solomayer $^{1}$
}

Received: 18 January 2021 / Accepted: 9 April 2021 / Published online: 3 May 2021

(c) The Author(s) 2021

\begin{abstract}
Purpose Vaginal cuff dehiscence (VCD) is one of the major surgical complications following hysterectomy with data on incidence rates varying largely and studies assessing risk factors being sparse with contradictive results. The aim of this study was to assess the incidence rate of and risk factors for VCD in a homogenous cohort of women treated for benign uterine pathologies via total laparoscopic hysterectomy (TLH) with standardized follow-up.

Methods All patients undergoing TLH at the Department of Gynecology and Obstetrics, Saarland University Hospital between November 2010 and February 2019 were retrospectively identified from a prospectively maintained service database. Results VCD occurred in 18 (2.9\%) of 617 patients included. In univariate and multivariate analyses, a lower level of surgeon laparoscopic expertise (odds ratio 3.19, 95\% confidence interval (CI) $1.0-9.38 ; p=0.03$ ) and lower weight of removed uterus (odds ratio $0.99,95 \%$ CI $0.98-0.99 ; p=0.02$ ) were associated positively with the risk of VCD.

Conclusion In this homogenous cohort undergoing TLH, laparoscopic expertise and uterine weight influenced the risk of postoperative VCD. These findings might help to further reduce the rate of this complication.
\end{abstract}

Keywords Vaginal cuff dehiscence $\cdot$ Total laparoscopic hysterectomy $\cdot$ Laparoscopic surgery $\cdot$ Risk factors $\cdot$ Complication · Gynecologic surgery

\section{Introduction}

Hysterectomy ranks among the most commonly performed gynecological surgical procedures [1]. Nearly 150,000 hysterectomies are performed annually in Germany [2].

Julia Caroline Radosa

Julia.radosa@uks.eu

1 Department of Gynecology and Obstetrics, Saarland University Hospital, Kirrbergerstraße 100, 66421 Homburg, Saar, Germany

2 Department of Gynecology and Obstetrics, Klinikum Bremen-Nord, Bremen, Germany

3 Department of Business and Psychology, University of Applied Sciences Europe, Berlin, Germany

4 Department of Radiology, Dresden University Hospital, Dresden, Germany

5 Institute of Medical Biometry, Epidemiology and Medical Informatics, Saarland University Hospital, Homburg, Saar, Germany
Eighty-five percent of these surgeries are elective interventions, performed due to benign uterine pathologies [3]. Vaginal hysterectomy has been the traditional standard-ofcare procedure for surgical uterus removal, but a gradual shift has occurred in surgical gynecology in the past 2 decades from vaginal and abdominal approaches to minimally invasive techniques, with increased performance of total laparoscopic hysterectomy (TLH) [4]. Major advantages of TLH over open procedures are reduced postoperative pain, faster recovery, and shorter hospitalization [5]. However, a notable disadvantage is the higher incidence of vaginal cuff dehiscence (VCD), defined as the separation of the previously sutured vaginal incision [6]. Although VCD is a rare complication, the evisceration of abdominal or pelvic organs through the vaginal breach can lead to serious sequelae, such as bowel injury, peritonitis, necrosis, and sepsis; regardless of its extent, VCD necessitates additional surgery in most cases $[7,8]$. VCD occurs significantly more frequently after TLH $(0.64-5.4 \%)$ than after abdominal $(0.38 \%)$, vaginal $(0.11 \%)$, and laparoscopically assisted 
$(0.46-1.5 \%)$ procedures $[9,10]$. Electrosurgery, previous radiation therapy, pelvic floor defects, and early postoperative sexual intercourse have been associated with the occurrence of VCD in general, but data on surgery-related risk factors for post-TLH VCD are sparse and contradictory [2, $11,12]$. Given the paucity of data and the high variation on the incidence of VCD following TLH in the current literature, we aimed to assess the frequency of and risk factors for VCD following TLH performed for benign uterine pathologies in a large cohort treated at a laparoscopic tertiary referral center.

\section{Materials and methods}

All patients who underwent TLH due to benign uterine disorders between November 2010 and February 2019 at the Department of Gynecology and Obstetrics, Saarland University Hospital, Homburg, Germany, were identified retrospectively through a prospectively maintained service database. The study was approved by the Saarland Institutional Review Board (Reference No. 85/16) and registered with the German Clinical Trials Register (DRKS) (No. DRKS00009904).

All methods were carried out in accordance with respective guidelines and regulations. All TLHs were performed under general anesthesia at Department of Gynecology and Obstetrics at Saarland University Hospital Homburg, Germany, where the procedure has been the standard surgical approach for hysterectomy since 2009. The surgical techniques applied are described in detail elsewhere [13-15]. Preoperatively, all patients provided medical histories and underwent gynecological examination, transvaginal ultrasound, and ultrasound of the kidneys. Basic laboratory tests were performed on admission.

All procedures were performed using a vaginal manipulator (Hohl; Karl Storz SE \& Co. KG, Tuttlingen, Germany). Colpotomy of the vaginal fornix was performed with a monopolar hook (Karl Storz SE \& Co. KG, Tuttlingen, Germany). The vaginal vault was closed with single-layer laparoscopic suturing (single knot or running) using Vicryl 1-CT-1 (Ethicon Inc., Somerville, NJ, USA) and an intracorporeal knot technique. All patients received perioperative antibiotics (cefuroxime, $1.5 \mathrm{~g}$; Fresenius Kabi, Bad Homburg, Germany), indwelling urinary catheters, and low-molecular-weight heparin (enoxaparin sodium, $40 \mathrm{mg}$; Sanofi, Paris, France) as thromboembolism prophylaxis postoperatively. All patients underwent standardized followup, including gynecological examination and transvaginal sonography, at 6 weeks postoperatively, and were interviewed by telephone about the occurrence of VCD. Patients with incomplete datasets, including missing follow-up information, were excluded from the study.
VCD was defined as full-thickness separation of the anterior and posterior edges of the vaginal cuff, with or without bowel evisceration categorized as complete when the separation involved the entire length of the vaginal vault and as partial when it involved only part of the incision $[11,16]$. Evisceration was defined as the expulsion of abdominal content through a vaginal cuff defect. VCD repair was conducted laparoscopically with complete inspection of the abdominal cavity for hematoma, abscess, or bowel injury, followed by irrigation, excision of necrotic tissue, and re-suturing using single-knot technique with Vicryl 1-CT-1 (Ethicon Inc., Somerville, USA). In cases of minimal dehiscence and no clinical or sonographic suspicion of hematoma, abscess, or bowel injury, vaginal repair with single-knot suturing was performed.

Clinical data comprising patients' age (years), body mass index $\left(\mathrm{kg} / \mathrm{m}^{2}\right)$, menopausal status, childbirth (number, mode of delivery) and surgeries performed in the past (measured by a surgery score: 0 points: no previous surgery, 1 point: previous laparoscopic surgery 2 points: open surgery, e.g., laparotomy, cesarean section) described by Boosz et al. and surgical parameters such as duration of surgery (minutes), performance of consecutive adhesiolysis or ureterolysis, suturing technique (single stitches vs. running non-overcast suture), duration of surgery (minutes), postoperative complications (according to the Clavien-Dindo classification of surgical complications), interval between surgery and first sexual intercourse (weeks), time between surgery and detection of VCD (days) and laparoscopic expertise of the surgeon assessed according to the GESEA program (Gynaecologic Endoscopic Surgical Education and Assessment) of the European Academy of Gynaecological Surgery and the European Society for Gynaecologic Endoscopy (ESGE) (GESEA level 1 (Bachelor) and GESEA level 2 [minimal invasive Gynaecological Surgeon (MIGS)] [17-20].

\section{Statistical analysis}

Data were collected in an Excel database (Excel 2014, Microsoft Corporation, Redmond, WA, USA). The Kolmogorov-Smirnov test was used to assess normality distribution for quantitative variables. As the data were non-normally distributed, we used the Mann-Whitney $U$ test to assess differences between groups. For categorical variables, we used Pearson's Chi-squared test for group comparisons. For multiple analysis, binary logistic regression with stepwise forward and backward selection was used to identify factors and possible confounders associated with the occurrence of VCD. Statistical tests were two-sided and subject to a significance level of $5 \%$. Due to the explorative nature of the investigation, we did not account for the issue of multiple testing and thus report unadjusted $P$ values. The statistical 
analyses were performed using SPSS (Version 19; SPSS Inc., Chicago, IL, USA).

\section{Results}

\section{Patient characteristics}

Six hundred and sixty-three patients who received TLH for benign uterine pathologies between November 2010 and September 2018 at the Department of Gynecology and Obstetrics, Saarland University Hospital, Homburg, Germany were identified from the service database. Four patients were excluded because of malignant final histology reports, 18 patients were excluded because of nonattendance of 6 weeks postoperative follow-up visits, and 24 patients were excluded because of missing further postoperative information on occurrence of VCD, leaving a total of 617 patients included in the final analysis. Detailed patient characteristics and surgical parameters are shown in Tables 1 and 2. Postoperative VCD occurred in 18 patients (incidence rate, $2.9 \%$ ). Median time between surgery and detection of VCD were 12 days (range 0-69). Patients with VCD presented with vaginal bleeding or discharge $(n=12)$, abdominal pain $(n=5)$, and vaginal pressure $(n=1)$. Three patients had complete VCD, with the evisceration of abdominal content through the dehiscence in two cases. Sixteen patients with VCD required re-operation, via laparoscopy in 13 patients and via single-knot vaginal closure in 3 patients with minor dehiscence (Table 3).

Table 1 Patient's characteristics $(n=617)$

\begin{tabular}{ll}
\hline & $\begin{array}{l}n=617 \\
\text { Median (Min-Max) }\end{array}$ \\
\hline Age (years) & $47(26-82)$ \\
BMI $\left(\mathrm{kg} / \mathrm{m}^{2}\right)$ & $25.7(19-54.6)$ \\
Parity & $1(0-7)$ \\
Number of vaginal deliveries & $1(0-7)$ \\
Previous surgery score & $1(0-16)$ \\
& $N(\%)$ \\
Menopausal status & \\
Pre-/perimenopausal & $494(80)$ \\
Postmenopausal & $123(20)$ \\
Smoker & $109(18)$ \\
Main indications for hysterectomy $(\%)$ & \\
Symptomatic uterine fibroids & $366(59)$ \\
Endometriosis & $110(18)$ \\
Cervical dysplasia & $49(8)$ \\
Uterine prolaps & $48(8)$ \\
Other & $44(7)$ \\
\hline
\end{tabular}

Table 2 Surgical outcomes $(n=617)$

\begin{tabular}{ll}
\hline & Median (Min-Max) \\
\hline Surgical parameters & \\
Duration of surgery (min) & $109(40-390)$ \\
Hemoglobin drop (g/dl) & $1.1(0-6.9)$ \\
Postoperative hospitalization (days) & $3(1-25)$ \\
Uterine weight (g) & $169(19-2148)$ \\
& $N(\%)$ \\
Adhesiolysis & $274(44)$ \\
Ureterolysis & $287(47)$ \\
Surgeons laparoscopic expertise & \\
GESEA level I & $297(48)$ \\
GESEA level II & $320(52)$ \\
Suturing technique & \\
Single knot suture & $519(84)$ \\
Running suture & $98(16)$ \\
Postoperative complications (Clavien-Dindo) & \\
Mild complications (I-II) & $16(2.6)$ \\
Severe complications (III-V) & $20(3.2)$ \\
First postoperative sexual intercourse <6 weeks & $119(19)$ \\
\hline
\end{tabular}

\section{Risk factor analysis}

In the univariate analysis, uterine weight and surgeon's laparoscopic expertise were associated with the incidence of VCD. The median weight of removed uterus was significantly lesser among patients with than among those without VCD [91 g, (range 55-321) vs. $171 \mathrm{~g}$, (range 19-2148), $P \leq 0.01]$. Significantly more patients with than without VCD were operated on by level 1 surgeons [14 (78\%) vs. 4 (22\%), $P \leq 0.01$ ] (Table 4). On multivariate analysis, the risk of VCD was associated with a lower level of surgeon laparoscopic expertise [odds ratio 3.19 (95\% CI 1.0-9.38); $P=0.03$ ] and lesser weight of removed uterus [odds ratio

Table 3 Incidence and presentation of VCD $(n=617)$

\begin{tabular}{ll}
\hline Vaginal cuff dehiscence (VCD) & $18(2.9 \%)$ \\
$\begin{array}{l}\text { Interval between surgery and occurrence of VCD [days; } \\
\text { median (range)] }\end{array}$ & $12(0-69)$ \\
& $n=18$ \\
Symptom presented with for VCD & \\
Vaginal bleeding & $10(55 \%)$ \\
Pain & $7(39 \%)$ \\
Vaginal pressure & $1(6 \%)$ \\
Type of dehiscence & \\
Partial dehiscence & $15(83 \%)$ \\
Complete dehiscence & $3(17 \%)$ \\
Evisceration & $2(11 \%)$ \\
Yes & $16(89 \%)$ \\
No &
\end{tabular}


Table 4 Univariate analysis of patient's characteristics and surgical outcome patients with vaginal cuff dehiscence (VCD) versus patients without $\mathrm{VCD}$ $(n=617)$

\begin{tabular}{|c|c|c|c|}
\hline & $\begin{array}{l}\text { No VCD } \\
n=599\end{array}$ & $\begin{array}{l}\text { VCD } \\
n=18\end{array}$ & $P$ \\
\hline & Median (min-max) & & \\
\hline Age (years) & $46(26-82)$ & $45(29-72)$ & 0.75 \\
\hline BMI $\left(\mathrm{kg} / \mathrm{m}^{2}\right)$ & $25.8(19-54.6)$ & $24.7(20.6-48.2)$ & 0.29 \\
\hline Parity & $1(0-7)$ & $1.5(0-3)$ & 0.68 \\
\hline Number of vaginal deliveries & $1(0-7)$ & $0.5(0-2)$ & 0.52 \\
\hline \multirow[t]{2}{*}{ Previous surgery score } & $1(0-16)$ & $1(0-14)$ & 0.13 \\
\hline & $N(\%)$ & & \\
\hline Smoker & $105(18)$ & $4(22)$ & 0.36 \\
\hline Menopausal status & & & 0.49 \\
\hline Pre-/perimenopausal & $480(80)$ & $14(78)$ & \\
\hline Postmenopausal & $119(20)$ & $4(22)$ & \\
\hline Main indications for hysterectomy (\%) & & & 0.26 \\
\hline Symptomatic uterine fibroids & $359(60)$ & $7(39)$ & \\
\hline Endometriosis & $104(17)$ & $6(33)$ & \\
\hline Cervical dysplasia & $47(8)$ & $2(11)$ & \\
\hline Uterine prolaps & $46(8)$ & $2(11)$ & \\
\hline \multirow[t]{2}{*}{ Other } & $43(7)$ & $1(6)$ & \\
\hline & Median (min-max) & & \\
\hline \multicolumn{4}{|l|}{ Surgical parameters } \\
\hline Duration of surgery $(\mathrm{min})$ & $107(40-390)$ & $104(47-281)$ & 0.51 \\
\hline Hemoglobin drop (g/dl) & $1.2(0-6.9)$ & $1.3(0-3.7)$ & 0.6 \\
\hline Postoperative hospitalization (days) & $3(1-25)$ & $4(2-14)$ & 0.29 \\
\hline \multirow[t]{2}{*}{ Uterine weigth $(\mathrm{g})$} & $171(19-2148)$ & $91(55-321)$ & $\leq \mathbf{0 . 0 1}$ \\
\hline & $N(\%)$ & & \\
\hline Adhesiolysis & $268(45)$ & $6(33)$ & 0.34 \\
\hline Ureterolysis & $278(46)$ & $9(50)$ & 0.76 \\
\hline Surgeons laparoscopic expertise & & & $\leq \mathbf{0 . 0 1}$ \\
\hline GESEA Level I & $283(47)$ & $14(78)$ & \\
\hline GESEA Level II & $316(53)$ & $4(22)$ & \\
\hline Suturing technique & & & 0.22 \\
\hline Single knot suture & $502(84)$ & $17(94)$ & \\
\hline Running suture & $97(16)$ & $1(6)$ & \\
\hline First postoperative sexual intercourse $<6$ weeks & $126(21)$ & $2(11)$ & 0.26 \\
\hline
\end{tabular}

0.99 (95\% CI 0.98-0.99); $P=0.02$ ]. The incidence of VCD was not associated with the duration of surgery, body mass index, or suturing technique (Table 5).

\section{Discussion}

In designing the present study, we sought to evaluate incidence and risk factors of VCD following total laparoscopic hysterectomy for benign uterine pathologies in a large cohort treated at a laparoscopic tertiary referral center, with a standardized follow-up. We found a rate of $2.9 \%$ for vaginal cuff dehiscence, which is in line with
Table 5 Multivariate analysis of factors associated with the incidence of vaginal cuff dehiscence

\begin{tabular}{lll}
\hline & Odds ratio (95\% CI) & $P$ \\
\hline $\begin{array}{l}\text { Surgeons laparoscopic } \\
\text { expertise (GESEA level I }\end{array}$ & $3.19(1.0-9.38)$ & 0.03 \\
$\quad$ vs. level II) & $0.99(0.98-0.99)$ & 0.02 \\
Uterine weigth (g) & $2.83(0.37-21.87)$ & 0.32 \\
Suturing technique (single- & & \\
$\quad$ knot suture vs. running & & \\
$\quad$ suture) & $0.97(9.0-1.05)$ & 0.47 \\
BMI $\left(\mathrm{kg} / \mathrm{m}^{2}\right)$ & $0.99(9.99-1.01)$ & 0.59 \\
Duration of surgery (min) & &
\end{tabular}


vaginal cuff dehiscence rates described in the literature of $0.64-5.4 \%$. Low surgeon laparoscopic expertise and low uterine weight were identified as risk factors for VCD. Two recent studies investigated this subject using similar designs [8, 11].

Rettermaier et al. conducted a retrospective analysis including 1876 patients undergoing TLH or robotic-assisted laparoscopic hysterectomy at a single institution and found a VCD incidence rate of $0.75 \%(n=14)$, which was lower than in this study (2.9\%). These discrepancies may be, possibly related to differences in study design. Two-thirds of procedures in that study were robotic-assisted laparoscopic hysterectomies, for which lower VCD rates $(0.4-4.1 \%)$ have been reported than for laparoscopic hysterectomy [21, 22]. In addition, the authors used barbed sutures for vaginal vault closure in most cases (no VCD occurred following this approach) and identified Vicryl suture use as a VCD risk factor [8]. Given the growing body of evidence confirming the protective effect of the usage of barbed suture to prevent $\mathrm{VCD}$, this might be a further explanation for the low VCD rate observed by the authors [23-25]. Finally, Rettermaier et al. identified VCD cases using coding data, which might have introduced selection bias and led to VCD underreporting due to inadequate procedure coding and loss to follow-up.

In a retrospective multi-institutional analysis including 12,398 patients undergoing hysterectomy (laparoscopic, vaginal or abdominal), the VCD rate was significantly higher for TLH $(0.64 \%)$ than for abdominal and vaginal hysterectomies $(0.2 \%$ and $0.13 \%)$, respectively, and laparoscopic vaginal cuff closure during TLH (performed in 20/38 VCD cases) was the main risk factor for VCD [11]. The VCD rate for TLH with vaginal closure $(0.24 \%)$ was similar to those for abdominal and vaginal hysterectomies. Differences in the VCD rate between that study and ours might be due to differences in assessment of VCD and follow-up. Surgeons' laparoscopic expertise may also have contributed, although the authors did not provide such information.

Higher VCD rates following TLH with laparoscopic (vs. vaginal) vault closure have been reported in institutions with moderate laparoscopic expertise [26]. On the contrary, a prospective randomized trial conducted by the Italian Society of Gynecologic Endoscopy including only highvolume (>500 gynecological interventions/year) Italian referral centers [27]. These results are in line with our finding that greater laparoscopic expertise showed a protective effect against incidence of VCD. Surgeon's experience with a surgical technique has been shown to have major impact on surgical outcomes and complication rates [20, 28]. Particularly laparoscopic suturing requires advanced training, and low proficiency may compromise the quality of vaginal cuff closure. Thus, reported differences in the incidence of
VCD according to surgical technique might reflect surgeons' expertise with the respective surgical approach, underlining the importance of training programs for minimally invasive surgeries [29].

We identified an inverse association between uterine weight and the incidence of VCD, which to our knowledge has not been reported previously [11, 29]. Greater mean uterine weights $(>300 \mathrm{~g})$ in VCD groups in previous studies assessing VCD rates discussed above, compared to the median weight of $120 \mathrm{~g}$ in the VCD group reported in our study, may have prevented identification of this variable as a risk factor. Our finding may be explained by the use of a small uterine-manipulator portio cap $(32 \mathrm{~mm})$ for patients with small uteri.

The usage of the small cap might lead to two possible complications explaining the higher VCD rate in this group. First in some cases, the small cap does not fully enclose the whole cervix, leading to vaginal vault opening above the level of the vaginal fornix, leaving cervical tissue in the vaginal vault (Fig. 1). This tissue might not adapt well, leading to necrosis and a higher VCD rate. In addition, smaller vaginal-tissue resection in patients with smaller uterus harbors the danger of greater thermal damage. These observations should be kept in mind for women with smaller uterus, who are typically not regarded as being at increased risk of postoperative complications. Special attention should be given to uterine-manipulator cap selection in these patients and cap placement should be checked for full uterine portio enclosure after uterine-manipulator application.

This study has several limitations. It was retrospective and may have involved reporting bias. However, patient identification from a prospectively maintained service database, and

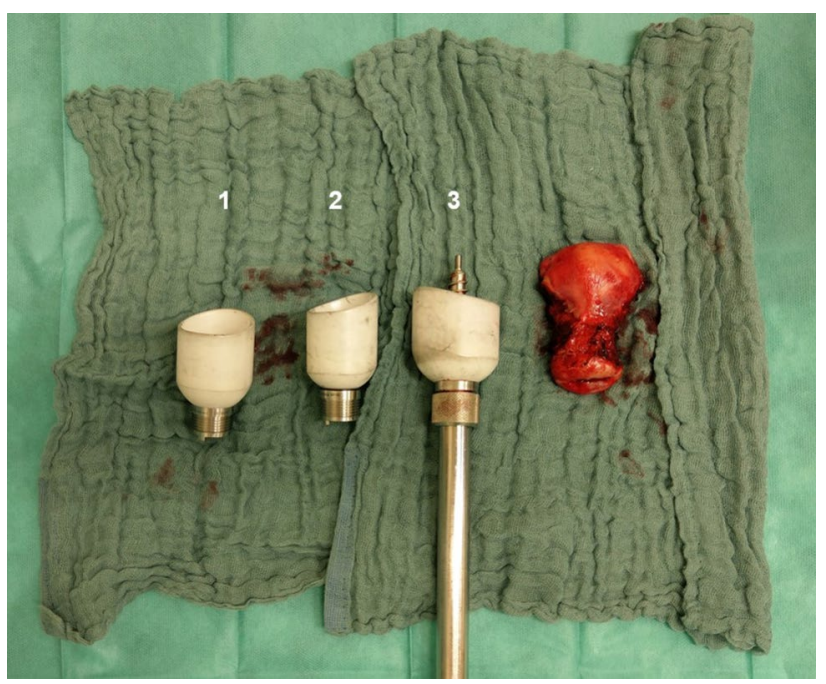

Fig. 1 Different portio caps used for total laparoscopic hysterectomy ((1) $-32 \mathrm{~mm},(2)-35 \mathrm{~mm}$, and (3)-40 $\mathrm{mm})$ 
the standardized follow-up, enhanced the study design and minimized the risk of VCD underreporting. This approach might also explain the higher VCD incidence than reported previously. Moreover, due to our standardized use of surgical suturing material, our findings might not be applicable to different suturing circumstances. Giving the possible protective effect of barbed suture use on VCD, this might impact the future incidence of VCD [8, 23, 24].

Since the median interval between surgery and occurrence of VCD were 12 days (0-69), most VCD were detected before the follow-up visit 6 weeks postoperatively and an earlier follow-up might have been more accurate. Another limitation of this study is the sample size. Although our sample was not small relative to those of other studies addressing similar questions, the rareness of VCD renders its statistical correlation with risk factors difficult $[9,24]$.

\section{Conclusion}

We found a VCD rate of $2.9 \%$ in this homogenous cohort treated with TLH for benign uterine pathologies at a single institution with a standardized follow-up and identified low surgeon's laparoscopic expertise and low uterine weight as factors associated with an increased risk of VCD. These findings emphasize the influence of surgeon's experience on the occurrence of VCD and help to identify patients with small uterus as an at-risk population. Our observations provide insight to minimize the risk of VCD, but additional prospective research is needed.

Acknowledgements The authors thank Dr. Jennifer Piehl for assistance in editing of the final draft of this manuscript.

Author contributions Regarding each author's contribution to authorship, JCR and MPR were responsible for conception and design of the study, interpretation of data and drafting the manuscript. CR, CR and SW performed statistical analysis of the data and revised the manuscript critically for intellectual content. EMB, LS, SF, and AW contributed substantially to the acquisition and analysis of the data. JZ, AH, UMR and FT were involved in designing the study with regard to surgical parameters and provided substantial contribution in interpretation of data and editing of the manuscript. EFS was involved in the acquisition of data and critical revision of the manuscript. All the authors reviewed the manuscript and contributed to the final submission.

Funding Open Access funding enabled and organized by Projekt DEAL. This work was funded by research grants from Saarland University Hospital (HOMFOR 2041601).

Availability of data and material The dataset used and analyzed during the current study is available from the corresponding author on reasonable request.

\section{Declarations}

Conflict of interest Dr. Julia Caroline Radosa, Dr. Christoph Gerlinger, Dr. Lisa Stotz, Professor Dr. Stefan Wagenpfeil and Professor Dr. Erich-Franz Solomayer declare no conflict of interest regarding the submitted work. Regarding interactions outside the submitted work, Dr. Julia Radosa has received travel grants from Medac GmbH (Wedel, Germany), Gedeon Richter (Budapest, Hungary), and Celgene (Summit, USA), Daiichi Sankyo (Tokyo, Japan), Pfizer (New York City, USA) and was an honorary speaker for Pfizer (New York City, USA) in the past. Dr. Lisa Stotz has received travel grants from Medac GmbH (Wedel, Germany) and Celgene (Summit, USA) outside the submitted work in the past. Dr. Christoph Gerlinger is a full-time employee of Bayer AG (Berlin, Germany). Professor Dr. Stefan Wagenpfeil is receiving grants from Saarland University (Saarbruecken, Germany) and Servier (Suresnes Cedex, France) outside the submitted work. Professor Dr. Erich-Franz Solomayer is receiving grants from the University of Saarland, Storz, and Erbe; personal fees and other compensation from Roche (Basel, Switzerland), Pfizer (New York City, USA), Celgene (Summit USA), Amgen (Thousand Oaks, USA), and Astra Zeneca (Cambridge, GB); other fees from Johnson \& Johnson (New Brunswick, USA), Novartis (Basel, Switzerland), Tesaro (Waltham, USA), Medac GmbH (Wedel, Germany), MSD (Kenilworth, USA), Vifor (Sankt Gallen, Switzerland), Gedeon Richter (Budapest, Hungary), Takeda (Tokyo, Japan), and AGE (Buchholz, Germany) outside the submitted work. Dr. Marc Philipp Radosa, Dr. Eva-Marie Braun, Dr. Sebastian Findeklee, Dr. Annette Wieczorek, Dr. Julia Zimmermann, Dr. Amr Hamza, Dr. Ferenc Zoltan Takacs, Professor Dr. Uda Mareke Risius and Dr. Christoph Radosa declare no potential conflict of interest regarding the submitted work and outside the submitted work.

Ethics approval This study was performed in line with the principles of the Declaration of Helsinki. Approval was granted by the Saarland Institutional Review Board (2nd November 2016/ Reference No. 85/16), the study was registered with the German Clinical Trials Register (DRKS) (No. DRKS00009904).

Open Access This article is licensed under a Creative Commons Attribution 4.0 International License, which permits use, sharing, adaptation, distribution and reproduction in any medium or format, as long as you give appropriate credit to the original author(s) and the source, provide a link to the Creative Commons licence, and indicate if changes were made. The images or other third party material in this article are included in the article's Creative Commons licence, unless indicated otherwise in a credit line to the material. If material is not included in the article's Creative Commons licence and your intended use is not permitted by statutory regulation or exceeds the permitted use, you will need to obtain permission directly from the copyright holder. To view a copy of this licence, visit http://creativecommons.org/licenses/by/4.0/.

\section{References}

1. Torpy JM, Lynm C, Glass RM (2004) JAMA patient page. Hysterectomy. JAMA 291(12):1526. https://doi.org/10.1001/jama.291. 12.1526

2. Radosa JC, Radosa CG, Kastl C, Mavrova R, Gabriel L, Gräber S, Wagenpfeil G, Baum S, Hamza A, Joukhadar R, Juhasz-Böss I, Heimes AS, Meyberg-Solomayer G, Solomayer EF, Radosa MP (2016) Influence of the preoperative decision-making process on the postoperative outcome after hysterectomy for benign uterine 
pathologies. Geburtshilfe Frauenheilkd 76(4):383-389. https:// doi.org/10.1055/s-0041-110396

3. Lethaby A, Mukhopadhyay A, Naik R (2012) Total versus subtotal hysterectomy for benign gynaecological conditions. Cochrane Database Syst Rev. https://doi.org/10.1002/14651858.CD004993. pub3

4. Fortin C, Hur C, Falcone T (2019) Impact of laparoscopic hysterectomy on quality of Life. J Minim Invasive Gynecol 26(2):219 232. https://doi.org/10.1016/j.jmig.2018.08.019

5. Kongwattanakul K, Khampitak K (2012) Comparison of laparoscopically assisted vaginal hysterectomy and abdominal hysterectomy: a randomized controlled trial. J Minim Invasive Gynecol 19(1):89-94. https://doi.org/10.1016/j.jmig.2011.10.003

6. Nezhat C, Kennedy Burns M, Wood M, Nezhat C, Nezhat A, Nezhat F (2018) Vaginal cuff dehiscence and evisceration: a review. Obstet Gynecol 132(4):972-985. https://doi.org/10.1097/ AOG.0000000000002852

7. Jeung IC, Baek JM, Park EK, Lee HN, Kim CJ, Park TC, Lee YS (2010) A prospective comparison of vaginal stump suturing techniques during total laparoscopic hysterectomy. Arch Gynecol Obstet 282(6):631-638. https://doi.org/10.1007/ s00404-009-1300-0

8. Rettenmaier MA, Abaid LN, Brown JV 3rd, Mendivil AA, Lopez KL, Goldstein BH (2015) Dramatically reduced incidence of vaginal cuff dehiscence in gynecologic patients undergoing endoscopic closure with barbed sutures: a retrospective cohort study. Int J Surg 19:27-30. https://doi.org/10.1016/j.jjsu.2015.05.007

9. Hur HC, Donnellan N, Mansuria S, Barber RE, Guido R, Lee T (2011) Vaginal cuff dehiscence after different modes of hysterectomy. Obstet Gynecol 118(4):794-801. https://doi.org/10.1097/ AOG.0b013e31822f1c92

10. Landeen LB, Hultgren EM, Kapsch TM, Mallory PW (2016) Vaginal cuff dehiscence: a randomized trial comparing robotic vaginal cuff closure methods. J Robot Surg 10(4):337-341. https:// doi.org/10.1007/s11701-016-0604-x

11. Uccella S, Ceccaroni M, Cromi A, Malzoni M, Berretta R, De Iaco P, Roviglione G, Bogani G, Minelli L, Ghezzi F (2012) Vaginal cuff dehiscence in a series of 12,398 hysterectomies: effect of different types of colpotomy and vaginal closure. Obstet Gynecol 120(3):516-523. https://doi.org/10.1097/AOG.0b013e3182 $64 \mathrm{f} 848$

12. Blikkendaal MD, Twijnstra AR, Pacquee SC, Rhemrev JP, Smeets MJ, de Kroon CD, Jansen FW (2012) Vaginal cuff dehiscence in laparoscopic hysterectomy: influence of various suturing methods of the vaginal vault. Gynecol Surg 9(4):393-400. https://doi.org/ 10.1007/s10397-012-0745-5

13. Radosa JC, Radosa CG, Mavrova R, Wagenpfeil S, Hamza A, Joukhadar R, Baum S, Karsten M, Juhasz-Boess I, Solomayer EF, Radosa MP (2016) Postoperative quality of life and sexual function in premenopausal women undergoing laparoscopic myomectomy for symptomatic fibroids: a prospective observational cohort study. PLoS ONE 11(11):e0166659. https://doi.org/10.1371/journ al.pone.0166659

14. Radosa JC, Radosa MP, Mavrova R, Rody A, Juhasz-Böss I, Bardens D, Brün K, Solomayer EF, Baum S (2013) Five minutes of extended assisted ventilation with an open umbilical trocar valve significantly reduces postoperative abdominal and shoulder pain in patients undergoing laparoscopic hysterectomy. Eur $\mathbf{J}$ Obstet Gynecol Reprod Biol 171(1):122-127. https://doi.org/10. 1016/j.ejogrb.2013.08.014

15. Bojahr B, Tchartchian G, Ohlinger R (2009) Laparoscopic supracervical hysterectomy: a retrospective analysis of 1000 cases. JSLS 13(2):129-134

16. Kim MJ, Kim S, Bae HS, Lee JK, Lee NW, Song JY (2014) Evaluation of risk factors of vaginal cuff dehiscence after hysterectomy.
Obstet Gynecol Sci 57(2):136-143. https://doi.org/10.5468/ogs. 2014.57.2.136

17. Boosz A, Haeberle L, Renner SP, Thiel FC, Mehlhorn G, Beckmann MW, Mueller A (2014) Comparison of reoperation rates, perioperative outcomes in women with endometrial cancer when the standard of care shifts from open surgery to laparoscopy. Arch Gynecol Obstet 290(6):1215-1220. https://doi.org/10.1007/ s00404-014-3347-9

18. Radosa MP, Meyberg-Solomayer G, Radosa J, Vorwergk J, Oettler K, Mothes A, Baum S, Juhasz-Boess I, Petri E, Solomayer EF, Runnebaum IB (2014) Standardised registration of surgical complications in laparoscopic-gynaecological therapeutic procedures using the Clavien-Dindo classification. Geburtshilfe Frauenheilkd 74(8):752-758. https://doi.org/10.1055/s-0034-1382925

19. Campo R, Wattiez A, Tanos V, Di Spiezio SA, Grimbizis G, Wallwiener D, Brucker S, Puga M, Molinas R, O'Donovan P, Deprest J, Van Belle Y, Lissens A, Herrmann A, Tahir M, Benedetto C, Siebert I, Rabischong B, De Wilde RL (2016) Gynaecological endoscopic surgical education and assessment. A diploma programme in gynaecological endoscopic surgery. Eur J Obstet Gynecol Reprod Biol 199:183-186. https://doi.org/10.1016/j. ejogrb.2016.02.003

20. Clavien PA, Barkun J, de Oliveira ML, Vauthey JN, Dindo D, Schulick RD, de Santibañes E, Pekolj J, Slankamenac K, Bassi C, Graf R, Vonlanthen R, Padbury R, Cameron JL, Makuuchi M (2009) The Clavien-Dindo classification of surgical complications: five-year experience. Ann Surg 250(2):187-196. https:// doi.org/10.1097/SLA.0b013e3181b13ca2

21. Kashani S, Gallo T, Sargent A, Elsahwi K, Silasi DA, Azodi M (2012) Vaginal cuff dehiscence in robotic-assisted total hysterectomy. JSLS 16(4):530-536. https://doi.org/10.4293/108680812X 13462882736817

22. Ala-Nissilä S, Laurikainen E, Mäkinen J, Jokimaa V (2019) Vaginal cuff dehiscence is observed in a higher rate after total laparoscopic hysterectomy compared with other types of hysterectomy. Acta Obstet Gynecol Scand 98(1):44-50. https://doi.org/10.1111/ aogs. 13459

23. Uccella S, Casarin J, Marconi N, Gisone B, Sturla D, Podestà Alluvion C, Candeloro I, Ghezzi F (2015) Incidence and prevention of vaginal cuff dehiscence following laparoscopic and robotic hysterectomy: a systematic review and meta-analysis. J Minim Invasive Gynecol 22(6S):S40. https://doi.org/10.1016/j.jmig.2015. 08.112

24. Siedhoff MT, Yunker AC, Steege JF (2011) Decreased incidence of vaginal cuff dehiscence after laparoscopic closure with bidirectional barbed suture. J Minim Invasive Gynecol 18(2):218-223. https://doi.org/10.1016/j.jmig.2011.01.002

25. Karacan T, Ozyurek E, Usta T, Odacilar E, Hanli U, Kovalak E, Dayan H (2018) Comparison of barbed unidirectional suture with figure-of-eight standard sutures in vaginal cuff closure in total laparoscopic hysterectomy. J Obstet Gynaecol 38(6):842-847. https://doi.org/10.1080/01443615.2017.1416597

26. Mäkinen J, Johansson J, Tomás C, Tomás E, Heinonen PK, Laatikainen T, Kauko M, Heikkinen AM, Sjöberg J (2001) Morbidity of 10110 hysterectomies by type of approach. Hum Reprod 16(7):1473-1478. https://doi.org/10.1093/humrep/16.7.1473

27. Uccella S, Malzoni M, Cromi A, Seracchioli R, Ciravolo G, Fanfani F, Shakir F, Gueli Alletti S, Legge F, Berretta R, Corrado G, Casarella L, Donarini P, Zanello M, Perrone E, Gisone B, Vizza E, Scambia G, Ghezzi F (2018) Laparoscopic vs transvaginal cuff closure after total laparoscopic hysterectomy: a randomized trial by the Italian Society of Gynecologic Endoscopy. Am J Obstet Gynecol 218(5):500.e1-500.e13. https://doi.org/10.1016/j.ajog. 2018.01.029

28. Mavrova R, Radosa JC, Wagenpfeil G, Hamza A, Solomayer EF, Juhasz-Böss I (2016) Learning curves for laparoscopic 
hysterectomy after implementation of minimally invasive surgery. Int J Gynaecol Obstet 134(2):225-230. https://doi.org/10.1016/j. ijgo.2016.01.017

29. MacKoul P, Danilyants N, Sarfoh V, van der Does L, Kazi N (2020) A retrospective review of vaginal cuff dehiscence: comparing absorbable and nonabsorbable sutures. J Minim Invasive
Gynecol 27(1):122-128. https://doi.org/10.1016/j.jmig.2019.03. 002

Publisher's Note Springer Nature remains neutral with regard to jurisdictional claims in published maps and institutional affiliations. 